\title{
Strategic Directions to Enhance Clinical Placements with in Primary Health Care
}

\section{Leanne Boyd*}

Department of Community Emergency Health and Paramedic Practice, Monash University, Australia

The quality and sustainability of primary healthcare depends on an adequate workforce. Universities play a major role in the training of health practitioners to fulfill this workforce need and there has been a substantial increase in professional entry university places over recent years to cater to the growing demand [1]. This has resulted in a severe shortage of clinical placements within all health related disciplines [2]. A number of factors have contributed to this impasse such as greater demand for services, increased patient acuity, resource constraints and overburdened clinical staff [3]. Placements in primary health agencies are under considerable strain from increased student numbers and inadequately funded and supported student-mentoring programs. The inability to meet current and projected demand for placements has been labeled a crisis [4].

The simple solution would be to reduce the number or length of current available primary care placements within all health disciplines. This option, however, is not well supported by either students or employers who expect that clinical competence is developed by applying knowledge and skills in the clinical setting [5]. While there is some evidence that suggests that clinical placements are not a critical component of health professionals education [6], the prevailing view is that the "theoretical knowledge base and cognitive development of professionals cannot be separated from practice" [7]. Students rate clinical placements highly and believe it is an integral component of their student experience [4]. Given this, the adoption of a strategic approach to better manage clinical placements within primary health care is essential. Five priorities are highlighted for consideration:

\section{Enhancing Clinical Placement Capacity}

Demand for places in many primary health agencies has reached saturation point and yet some venues are under utilized. Placements within aged care, community health and rural health have been particularly sporadic. Within Australia, the National Health Workforce Taskforce (NHWT) identified a significant gap in the knowledge of current clinical training load, its distribution and any under utilized capacity [5]. The proposed Health Workforce Australia (HWA) project to gather national data on current clinical training load, capacity being utilized and its distribution for each profession will go a long way to address this issue. Once identified, under utilized venues can be used to capacity and a more equitable distribution of student load can occur.

The Australian Department of Health have established an Expanded Settings Project to promote clinical placement activity in non-acute health settings [8]. Currently, key stakeholder consultation is occurring to inform the development of these reforms, prior to the implementation of a national system.

\section{Stronger Links Between Universities and Placement Providers}

The establishment of effective pathways for reciprocal communication between universities and placement providers is essential to proactively identify and remediate issues. A number of
Australian Universities have set up Clinical Schools in rural Australia, aiming to attract and retain medical graduates within rural regions. These schools have established networks with local hospitals and could be expanded (with adequate incentives!) to include students from other health disciplines. Clinical schools foster an increased presence in teaching hospitals and better engagement with clinical educators. They are expensive to establish and maintain particularly for smaller disciplines and therefore involvement in established schools is advocated.

\section{Improving the Quality of the Clinical Placement Experience}

To enhance the quality of clinical education within all clinical placement domains a targeted approach is necessary. Quality assurance in higher education has risen to the top of the policy agenda in many nations and graduates must attain new skills and a range of competencies to enter a more complex and interdependent world [9]. This must extend to all the clinical placement domains as students are charged for clinical placement units and have a right to expect a quality educational experience.

\section{To Create Innovative and Sustainable Alternatives and Adjuncts to Clinical Placements}

Low, Mid and High fidelity simulation offers an opportunity to develop students' clinical competence and clinical decision-making skills. This is seen more as a legitimate means of preparing students for clinical practice rather than an option for reducing clinical placement time during health courses [10]. Peer role-play and standardized patients are also being explored within primary health care curriculum to augment clinical placement experiences $[10,11]$. Given the expense, time and resources required for simulated patients, peer role-play is currently gaining strong interest within primary health care settings [11].

\section{To Ensure that Clinical Placements Remain Financially Viable}

Requests for payment for clinical places have been occurring for some time. It is obvious that an element of cost is incurred by the placement venue and it is unreasonable to expect them to absorb this cost. Primary Care Facilities that provide clinical placements

*Corresponding author: Leanne Boyd, Department of Community Emergency Health and Paramedic Practice, Monash University, Australia, E-mail: leanne.boyd@monash.edu

Received March 05, 2012; Accepted March 07, 2012; Published March 09, 2012

Citation: Boyd L (2012) Strategic Directions to Enhance Clinical Placements with in Primary Health Care. Primary Health Care 2:e102. doi:10.4172/21671079.1000e102

Copyright: (c) 2012 Boyd L. This is an open-access article distributed under the terms of the Creative Commons Attribution License, which permits unrestricted use, distribution, and reproduction in any medium, provided the original author and source are credited. 
are charging universities or refusing to accept students due to a lack of resource support [12]. Government funding and incentives are necessary to encourage primary care providers to accept students and provide a quality clinical experience.

\section{Future Directions}

A collaborative and collegial analysis of the problems must be undertaken to ensure that the most appropriate plan for the future is developed and progressed. In Australia, this is currently occurring at the highest level with the NHWT and HWA. The issues identified are complex, multidisciplinary and multidimensional and no single strategy will suffice. The NHWT Clinical Training project plans five streams of work to inform their recommendations for effective, sustainable approaches to the delivery, organization, efficiency and capacity of clinical training in Australia [13]. These are:

\section{Stream 1: Data organization and capacity}

National data will be gathered on current clinical training load, capacity being utilized and its distribution between professions.

\section{Stream 2: Funding arrangements and responsibilities}

The current national and state funding policy environment is being examined for perceived risks and inequities.

\section{Stream 3: New models and innovation}

Alternative models of clinical training are being investigated and innovative strategies to expand capacity are being sought.

\section{Stream 4: Governance and organization}

This stream is reviewing the organizational barriers that are currently constraining the systems' capacity to provide high quality clinical training.

\section{Stream 5: Quality, efficiency and effectiveness}

The need to develop relevant indicators of quality, efficiency and effectiveness that are clearly evident from the lack of consistency in accreditation standards and the related costs that are incurred will be examined [13]. Rigorous evaluation of these streams will inform future directions for primary health care placements both nationally and internationally.

\section{References}

1. Health Workforce Australia 2010 (2010) Clinical Supervisor Support Program.

2. Productivity Commision (2005) Australia's Health Workforce Research Report

3. Zurn P, Poz MRD, Stilwell B, Adams O (2004) Imbalance in the health workforce. Human Resources for Health 2: 300-312.

4. Health professions Council of Australia (2004) Solving the crisis in clinical education for Australia's health professions.

5. National Health Workforce Taskforce (2008) Data, capacity and clinica placements across Australia: a discussion paper.

6. Battersby D, Hemmings L (1991) Clinical performance of university nursing graduates. Aust J Adv Nurs 30: 30-34.

7. Yielder $J$ (2004) An integrated model of professional expertise and its implications for higher education. International Journal of Lifelong Education 23: $60-80$.

8. State Government of Victoria A, Department of Health (2010) Expanded Settings for Clinical Placements.

9. Altbach PG, Reisberg L, Rumbley LE (2009) Trends in Global Higher Education: Tracking an Academic Revolution. A Report Prepared for the UNESCO 2009 World Conference on Higher Education.

10. Barrows HS (1993) An overview of the uses of standardized patients for teaching and evaluating clinical skills. AAMC. Acad Med 68: 443-451.

11. Bosse HM, Nickel M, Huwendiek S, Jünger J, Schultz JH, et al. (2010) Peer role play and standardised patients in communication training: a comparative study on the student perspective on acceptability, realism, and perceived effect. BMC Med Educ 10: 27.

12. Australian Council of Pro Vice-Chancellors and Deans of Health Sciences (2008) Submission to the National Health and Hospitals Reform Commission.

13. National Health Workforce Taskforce, Health Education and Training (2008) Clinical placements across Australia: capturing data and understanding demand and capacity. 